\title{
Psycho-Educational Program to Improve Knowledge and Performance for Nurses Working with Schizophrenic Patients
}

\section{Fatma Attia Metwaly Abdo ${ }^{1}$, Ghada Mohamed Mourad ${ }^{2}$, Shewikar Tawfek El Bakry ${ }^{3}$ and Fathyea Said Sayed ${ }^{4}$}

(1)M.Sc. Nursing, Teacher in Technical Institute at Al-azhar University, Egypt, (2)Professor of Psychiatric and Mental Health Nursing, Faculty of Nursing, Ain Shams University, Egypt(3) Assistant Professor of Neuropsychiatry, Faculty of Medicine, Benha University, Egypt and (4) Assistant Professor of Psychiatric and Mental Health Nursing Faculty of Nursing, Benha University, Egypt

\begin{abstract}
Background: Schizophrenia is a severe psychiatric condition with specific characteristics that may constitute some obstacles for the therapeutic relationship. Aim of the study was to investigate the effect of psycho-educational program to improve knowledge and performance for nurses working with schizophrenic patients. Research design: A quasi-experimental research design was used to conduct this study. Setting: This study was conducted at Psychiatric and Mental Health Hospital in Benha city, Qalubia Governorate, Egypt Sample: A convenient sample technique was used to select 80 nurses. Tools of data collection: Three tools were used in this study; I- Structured interview questionnaire which included demographic data and professional characteristics of the studied nurses, II: Knowledge questionnaire and III: Management of schizophrenic patients' checklist. Results: The majority of nurses had unsatisfactory level of total performance towards schizophrenia before program implementation. While after program implementation, three-quarters of nurses had satisfactory level of total performance towards schizophrenia. Conclusion: There was a marked improvement in nurses' knowledge and performance with schizophrenic patients care post implementation of psycho-educational program with highly statistically significant difference between pre and post implementation of psychoeducational program. Recommendation: Designed educational program for nurses in psychiatric and mental health hospital; it would provide a framework for nurses' role for schizophrenic patient care.
\end{abstract}

Keywords: Psycho-Educational, Knowledge, Performance, Nurses Working, Schizophrenic Patients

\section{Introduction:}

Schizophrenia is a chronic mental disorder that affects early brain growth and interferes with an individual's ability to make good use of their common sense. The disease is life threatening and requires both care givers and the patients to work closely with each other towards its treatment (Lara Adeyemi \& Paul Musco, 2019).
Schizophrenia is a chronic psychological disorder with complex features that can cause therapeutic barriers. One of the main challenges being the difficulty of both the patient and the nurse in recognizing the symptoms (Pinho et al., 2017).

Chronic nature of schizophrenia needs the continuous and persistent engagement in addition to follow-ups with patients by nurse 
practitioners. It means that information sharing among patients and clinicians remains fundamental for making treatment decisions, which can support the patients in reaching their personal potential (Lara Adeyemi \& Paul Musco, 2019).

Schizophrenia is a serious psychiatric disorder with particular symptoms that can constitute certain barriers for the therapeutic relationship. The challenges in interpreting the symptomatology both by the patient and by the nurse represent one of the main obstacles ( Pinho et al., 2017).

Schizophrenic patients can be achieved through various efforts such as individual empowerment and a sense of duty on the patient's part and support from counseling hence the need to educate nurse practitioners in promoting medication compliance (Hasan and Musleh, 2017).

In Egypt, The most prevalent form of psychosis is schizophrenia, which accounts for the majority of inpatients in psychiatric hospitals (Semrau, et al., 2015).

The nursing assessment of the schizophrenic patient is a complex process in most cases, requiring the collection of data from several sources, since in the acute phase of the disease the patient is rarely able to give reliable information. It is important to make appeals to family members and significant others, as well as health records where they are available. A psychiatric assessment should be conducted first, in order to recognize the current symptomatology, such as delusions, hallucinations, disorganization, or negative symptomatology. In order to conduct an accurate diagnosis, the nurse must be familiar with the disorder's common habits (Pinho et al., 2017).

It is up to nurses to take technical measures (substance control, drug management), treatment attitude, optimize relationships with patients and the community, encourage well-being and enhance self-perception, often understand the client's background, and achieve social integration (Public Health England, 2017).

Skilled nurses require strategic reasoning capabilities to utilize them for effective treatment as the field of healthcare is quickly evolving. An training initiative is one way to do this (Pretoruis et al., 2016).

The nursing assessment of the schizophrenic patient is a complex process in most cases, requiring the collection of data from several sources, since in the acute phase of the disease the patient is rarely able to give reliable information. It is important to make appeals to family members and significant others, as well as health records where they are available. A psychiatric assessment should be conducted first, in order to recognize the current symptomatology, such as delusions, hallucinations, disorganization, or negative symptomatology. In order to conduct an accurate diagnosis, the nurse must be familiar with the disorder's common habits (Pinho et al., 2017).

Nurses have a responsibility to continue their studies after they have earned their license so that they can stay informed of medical advances and new science. In nursing, knowledge is a valuable weapon, and a well-educated nurse can mean the difference between life and death for a patient.Continuing education often provides $n$ urses with further career options; some nurses find themselves transitioning from nursing $\mathrm{w}$ ork to research. A degree or other training ma $\mathrm{y}$ lead to specialization or employment as a nu rse practitioner in a family practice environme nt (John, 2017).

\section{Significance of the study}

Schizophrenia is a severe psychiatric condition with unusual features that may 
render the clinical relationship challenging. Nursing care for these patients necessitates a high level of awareness, tolerance, and nonstigmatization of mental disease. To create an accurate and productive educational program, the nurse must be willing to look through the signs and recognize an individual in terrible psychiatric distress, depression, hopelessness, and incomprehension, who might also consider suicidal thoughts. (Pinho, Pereira, \& Chaves, 2017).

Negative views about mental health nursing tend to be related to a lack of expertise and skills in coping with emotionally unstable individuals on wards. Many respondents felt vulnerable, threatened, irritated, and unwilling to communicate with mentally ill people, and many felt threatened, threatened, annoyed, and unable to connect with mentally ill people. This means that trained nurses in general hospitals may have more experience and expertise in dealing with psychologically disturbed patients (International Council of Nurse (ICN), 2016).

\section{Aim of the Study:}

The aim of this study was to investigate the effect of psycho-educational program to improve knowledge and performance for nurses working with schizophrenic patients

\section{Research Hypothesis:}

Implementation of psycho-educational program for nurses working with schizophrenic patients will improve their knowledge and performance.

\section{Subjects and Methods}

\section{Research Design}

A quasi-experimental research design was used to conduct this study.

\section{Setting}

This study was conducted at Psychiatric and Mental Health Hospital in Benha city, Qalubia Governorate, which is affiliated to General Secretariat of Mental Health in Egypt. It has 5 departments (4 males and 1 female); with a capacity of 184 beds. It provides care for 141 Psychiatric patients.

\section{Sample:}

A convenient sample technique was used to select 80 nurses working at Psychiatric and Mental Health Hospital.

\section{Tools of Data Collection}

Three tools were used in this study;

\section{Tool I- Structured Interview Questionnaire:}

This tool developed by the researcher after reviewing the related national and international literature. It was written in a simple Arabic language to suit the understanding level of the study subject. It was used to collect data about nurses. It entails two parts as the following:

\section{Part 1: demographic data of the studied nurses}

This part was used to assess demographic data of nurses under study such as age, sex, and marital status.

\section{Part 2: Professional characteristics of the studied nurses}

This part was used to assess professional characteristics of nurses under study such as educational level, years of experience in psychiatric nursing, working in a psychiatric hospital previously and history of taking training programs in psychiatric nursing.

\section{Tool II: knowledge Questionnaire Sheet:}

It was adopted from Willetts \& Leff, (2003), modified by the researcher, translated 
into an Arabic language after reviewing the related literature, and reviewed by supervisors. It was used for assess nurses' knowledge about schizophrenia and its care.

The questioner was consisted of 29 closed ended questions in form of Multiple Choice Question (MCQ) to assess nurses' knowledge about schizophrenia and its care. It consists of five parts included: knowledge about schizophrenia (7 questions), knowledge about treatment of schizophrenia (4 questions), knowledge about care for a schizophrenic patient (10 questions), knowledge on relapse (5 questions) and knowledge about rehabilitation for schizophrenia patients (3 questions).

\section{Scoring system:}

A scoring system was followed to assess nurses' knowledge about schizophrenia and its care. The Questionnaire was contained of 29 questions, the total scores of the questionnaire were 29 grades, the right answer was scored as a single point and the wrong answer was scored as a zero point. These scores were summed and were converted into a percent score.

It was classified into 3 categories:

- Good knowledge if score $>70 \%$.

- Average knowledge if score from 50-70\%.

- Poor knowledge if score $<50 \%$.

Tool III: Management of Schizophrenic Patients Checklist:

It was adopted from Berkowitz \&

Heinl (1984), modified by the researcher after reviewing the related literature, and reviewed by supervisors. It was used to measure the strategies used in dealing with symptoms and difficult behaviors in mental illness.

The checklist consisted of 55 steps divided as Performance towards aggressive patients (14 steps), Performance towards sedative injection (6 steps), Performance towards suicidal patients (9 steps), Performance towards disturbed consciousness
(12 steps), Performance towards environment surrounding the patient (7 steps) and Performance towards dealing with the patient's family and relatives (7 steps). Each checklist was assigned a score according to sub-items.

The total score of nurses' practices were 55 grades, each item of performance towards aggressive patients and sedative injection was evaluated as "done" was taken one score and "not done" was taken zero score. While, each item in other domains was evaluated as "always" was taken two grade, "sometimes" was taken one grade, and "never" was taken zero. These scores were summed up and were converted into a percentage score. It was classified into 2 categories:

- Satisfactory level if score $\geq 80 \%$.

- Unsatisfactory level if score $<80 \%$.

Psycho-educational program for nurses working with schizophrenic patients: it was designed by the researcher based on current local and international related literatures using books, articles and scientific magazines. It was written in simple Arabic language. The educational program contained information about schizophrenia, relapse, treatment of schizophrenia, care for patients with schizophrenia and rehabilitation for patients with schizophrenia.

\section{Content and Face Validity and Reliability:}

Validity: It was ascertained by (5) experts in Psychiatric Mental Health Nursing expertise. Their opinions elicited regarding the format, layout, consistency, accuracy and relevancy of the tools.

Reliability analysis by measuring of internal consistency of the tool through Cronbach's Alpha test.

\begin{tabular}{|c|c|}
\hline Tool & $\begin{array}{c}\text { Coronbach } \\
\text { alpha test }\end{array}$ \\
\hline Knowledge & .840 \\
\hline Practice & .865 \\
\hline
\end{tabular}




\section{Ethical Considerations}

The research approval was obtained from the Faculty Ethical Committee before starting the study.

\section{The ethical research considerations include the following:}

Before the program began, the researcher outlined the study's aims and priorities to the nurses who will be involved and the nurses were granted verbal consent and a direct and simple interpretation based on their degree of comprehension. They ensured that all information collected was kept private and only used for testing purposes. The researcher was retaining the privacy and secrecy of the study's participants' results. The participants were told that they had the option of participating in the research or not, and that they had the freedom to withdraw at any moment.

\section{Pilot Study}

Carried out on 8 nurses those represent $10 \%$ of nurses at Psychiatric and Mental Health Hospital in Benha city, Qalubia Governorate, which is affiliated to General Secretariat of Mental Health in Egypt. In order to test the applicability of the constructed tools and the clarity of the included questions related to nurses' knowledge and practice regarding schizophrenia and its care. The pilot has also served to estimate the time needed for each subject to fill in the questions. According to the results of the pilot, some corrections and omissions of items were performed so the pilot nurses were not included in the main study sample.

\section{Field work}

The collection of data and application of psycho-educational program lasted over a period of ten months; starting at May 2019 and ending in December 2019, through the following phases:

\section{Assessment phase}

- The researcher visited the Psychiatric and Mental Health Hospital three days in Saturday, Sunday and Monday at morning shift (8a.m-2p.m) and afternoon shift (2pm-8pm) to collect data.

- The researcher obtained nurses' oral consent for participating in this study after explaining the aim of the study.

- The researcher starting the interviewing process by filling demographic data and professional data which took about 10 minutes then the questioner for knowledge was filled by nurses which take 20-25 minutes, while the checklist for assessing nurses' practice was filled by the researcher in 50-60 minutes while nurses given daily routine care.

- All information collected through data collection tools were interpreted for identifying individualized teaching needs.

- The researcher set up teaching plan covering all objectives. These objectives were categorized into general and specific objectives.

- The instructions resources and facilities were allocated (printed material and location of session that best serve the learners).

- The researcher determined the time table of sessions, teaching methods, media used and learner's activities.

- After data collection, the appointment for starting instructions sessions was detected and scheduled with the nurses for the following weeks. 
- The assessment phase and planning started from the beginning of May to the end of June 2019.

\section{Implementation phase}

- The teaching sessions were conducted in the rooms at Psychiatric and Mental Health Hospital training unit. The rooms were conditioned, quiet, had adequate lighting, well ventilated and furnished, and had adequate spacing for the place for implementing educational instructions activities.

- Total number of the sessions of educational instructions was 12 sessions. Each day of the training program was divided into two sessions, the duration of each session was 60 minutes for theoretical session and 90 minutes for practical session, and a break for 30 minutes was arranged between each session for 3 days per week.

- These sessions were conducted for small group; each group number didn't exceed six nurses. The booklet was given for every nurse.

- Implementation of educational instructions lasted over a period of 6 months for all nurses.

- Each session started by greeting the nurses, assessing nurses motivation for learning, getting feedback about what was given through the previous session and present the objectives of the new topic were taking into consideration using simple language to suit the educational level of the nurses.

- The implementation phase started from the beginning of July to the end of December 2019.

\section{Theoretical part included}

\section{Four sessions for theoretical part:}

- At the beginning of the first session, an orientation of educational instructions and its purpose took place. The importance and benefit of educational instructions were explained to the nurses to motivate them to follow instructions, which included in it.

- The researcher emphasized the importance of adherence to each step of educational instructions, and the rationale for and the benefit of engaging in each new behavior was explained. The researcher encouraged nurses to express their readiness for changing the performance.

- Motivation, problem solving and reinforcement techniques were used to enhanced active participation of the nurses in the educational sessions.

- The second teaching session included introduction to schizophrenia, definition, causes, types of schizophrenia, and people that at risk of developing schizophrenia. The third teaching session included symptoms, stages, complications and treatment of schizophrenia. The fourth teaching session included relapse, methods to alert the patient to prevent relapse and rehabilitation for schizophrenia patients.

\section{Practical part included}

\section{Eight sessions for practical part:}

- The first practical session included nurses' performance towards aggressive patients. The second practical session included nurses' performance towards sedative injection. The third practical session included nurses' performance towards suicidal patients. The fourth practical session included nurses' performance towards disturbed consciousness. The fifth practical session included nurses' performance towards environment 
surrounding the patient. The sixth practical session included application of relaxation exercises to patients, practice the deep breathing exercise and muscle relaxation exercise. The seventh practical session included different methods of dealing with hallucinations and delusions and methods to prevent relapse. The eighth practical session included nurses' performance towards dealing with the patient's family and relatives.

\section{Evaluation phase}

The evaluation phase emphasized on determining the effect of the psychoeducational program on nurses' knowledge and performance regarding schizophrenic patients by comparing results pre and immediately post using the previously mentioned tools. The evaluation phase finished at the end of February 2020.

\section{Statistical Analysis}

The statistical analysis of data was done by using the computer software of Microsoft Excel Program and Statistical Package for Social Science (SPSS) version 25 (SPSS Inc., Chicago, IL, USA). Data were presented using descriptive statistics in the form of frequencies and percentage for categorical data, the arithmetic mean (X) and standard deviation (SD) for quantitative data. Baseline differences between the group at pre- and post-were assessed using an independent t test for continuous variables, and $r$ - test to the correlation between the study variables.

\section{Significance of the results:}

- Highly significant at p-value $<0.01$.

- Statistically significant was considered at $\mathrm{p}$-value $<0.05$.

- Non-significant at $p$-value $>0.05$.

\section{Results:}

Table (1) showed that, more than half $(57.5 \%)$ of the studied nurses their age ranged between 30-<40 years with mean SD $35.25 \pm$ 4.11 year. Related to sex and marital status, more than two-thirds $(67.5 \%$ and $72.5 \%)$ of the studied nurses were male and married, respectively.

Table (2) presented that, half (50\%) of the studied nurses had diploma above average. Also, half $(50 \%)$ of the studied nurses their years of experience in psychiatric nursing ranged between $5-<10$ years with mean SD $8.30 \pm 1.84$ year. In addition, the majority $(85 \%)$ of the studied nurses working in a psychiatric hospital previously. Moreover, less than two-thirds $(65 \%)$ of them did not take a psychiatric nursing's training course.

Figure (1) showed that, $60 \%$ of nurses had poor level of total knowledge about schizophrenia and its care before program implementation. While after program implementation, $72.5 \%$ of nurses had good level of total knowledge.

Figure (2) showed that, the majority (85\%) of nurses had unsatisfactory level of total performance towards schizophrenia before program implementation. While after program implementation, three-quarters $(75 \%)$ of nurses had satisfactory level of total performance towards schizophrenia.

Table (3) revealed that, there was no statistically significant relation between total nurses' knowledge about schizophrenia and its care at pre- psycho-educational program and their all characteristics as age, gender and marital status at $(\mathrm{P}=>0.05)$.

Table (4) revealed that, there was highly statistically significant relation between total nurses' knowledge about schizophrenia and its care at pre- psycho-educational program and their professional characteristics as Academic 
qualification, working in a psychiatric hospital previously and history of taking a psychiatric nursing's training course at $(\mathrm{P}=\leq$ 0.001). also, there was statistically significant relation with their years of experience in psychiatric nursing at $(\mathrm{P}=\leq 0.001)$.

Table (5) revealed that, there was no statistically significant relation between total nurses' performance towards schizophrenia at pre- psycho-educational program and their all characteristics as age, gender and marital status at $(\mathrm{P}=>0.05)$.

Table (6) revealed that, there was highly statistically significant relation between total nurses' performance towards schizophrenia at pre- psycho-educational program and their professional characteristics as academic qualification, working in a psychiatric hospital previously and history of taking a psychiatric nursing's training course at $(\mathrm{P}=\leq$ 0.001). also, there was statistically significant relation with their years of experience in psychiatric nursing at $(\mathrm{P}=\leq 0.001)$.

Table (7) showed that, there was highly significant positive correlation between total nurses' knowledge towards schizophrenia and their total performance at pre and post implementation of psycho-educational program at $(\mathrm{P}=\leq 0.001)$.

Table (1): Number and percentage distribution of the studied nurses according to their demographic data $(n=80)$.

\begin{tabular}{|c|c|c|}
\hline Demographic data & No & $\%$ \\
\hline \multicolumn{3}{|l|}{ Age } \\
\hline $20-<30$ & 20 & 25 \\
\hline $30-<40$ & 46 & 57.5 \\
\hline$\geq 40$ & 14 & 17.5 \\
\hline $\mathrm{x}^{-}$S.D & \multicolumn{2}{|c|}{$35.25 \pm 4.11$} \\
\hline \multicolumn{3}{|l|}{ Sex } \\
\hline Male & 54 & 67.5 \\
\hline Female & 26 & 32.5 \\
\hline \multicolumn{3}{|l|}{ Marital status } \\
\hline Single & 16 & 20 \\
\hline Married & 58 & 72.5 \\
\hline Divorced & 4 & 5 \\
\hline Widowed & 2 & 2.5 \\
\hline
\end{tabular}


Table (2): Number and percentage distribution of the studied nurses according to their professional characteristics $(\mathbf{n}=\mathbf{8 0})$.

\begin{tabular}{|c|c|c|}
\hline Professional characteristics & No & $\%$ \\
\hline \multicolumn{3}{|l|}{ Academic qualification } \\
\hline Diploma in Nursing & 22 & 27.5 \\
\hline Diploma above average & 40 & 50 \\
\hline Bachelor of Nursing & 18 & 22.5 \\
\hline \multicolumn{3}{|c|}{ Years of Experience in Psychiatric Nursing } \\
\hline$<5$ & 14 & 17.5 \\
\hline $5-<10$ & 40 & 50 \\
\hline$\geq 10$ & 26 & 32.5 \\
\hline $\mathrm{x}^{-}$S.D & & \\
\hline \multicolumn{3}{|c|}{ Working in a psychiatric hospital previously } \\
\hline Yes & 12 & 15 \\
\hline No & 68 & 85 \\
\hline \multicolumn{3}{|c|}{ History of taking a psychiatric nursing's training course } \\
\hline Yes & 28 & 35 \\
\hline No & 52 & 65 \\
\hline
\end{tabular}

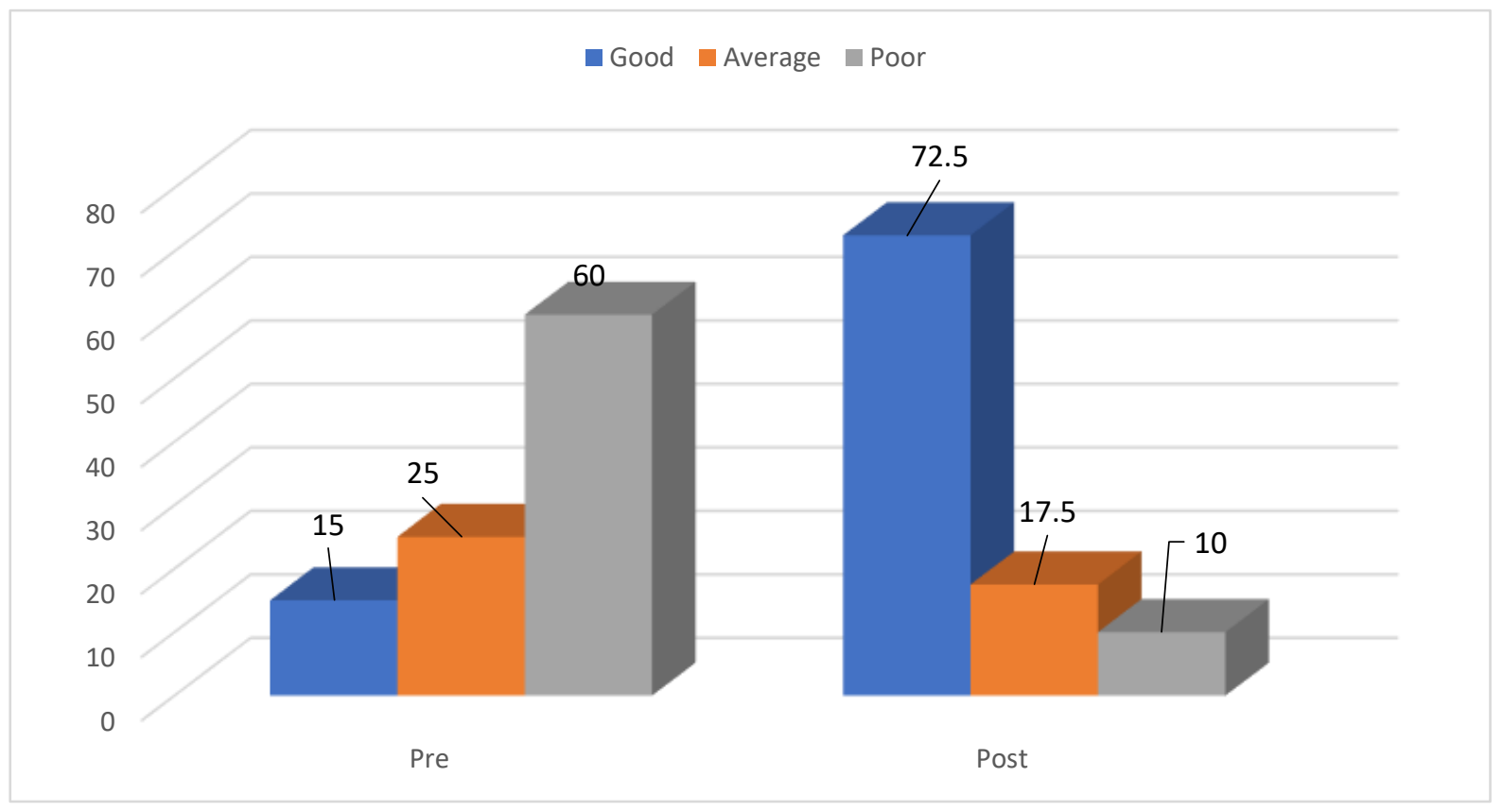

Figure (1): Distribution of the studied nurses at pre and post implementation of psychoeducational program regarding to their total knowledge about schizophrenia $(n=80)$. 


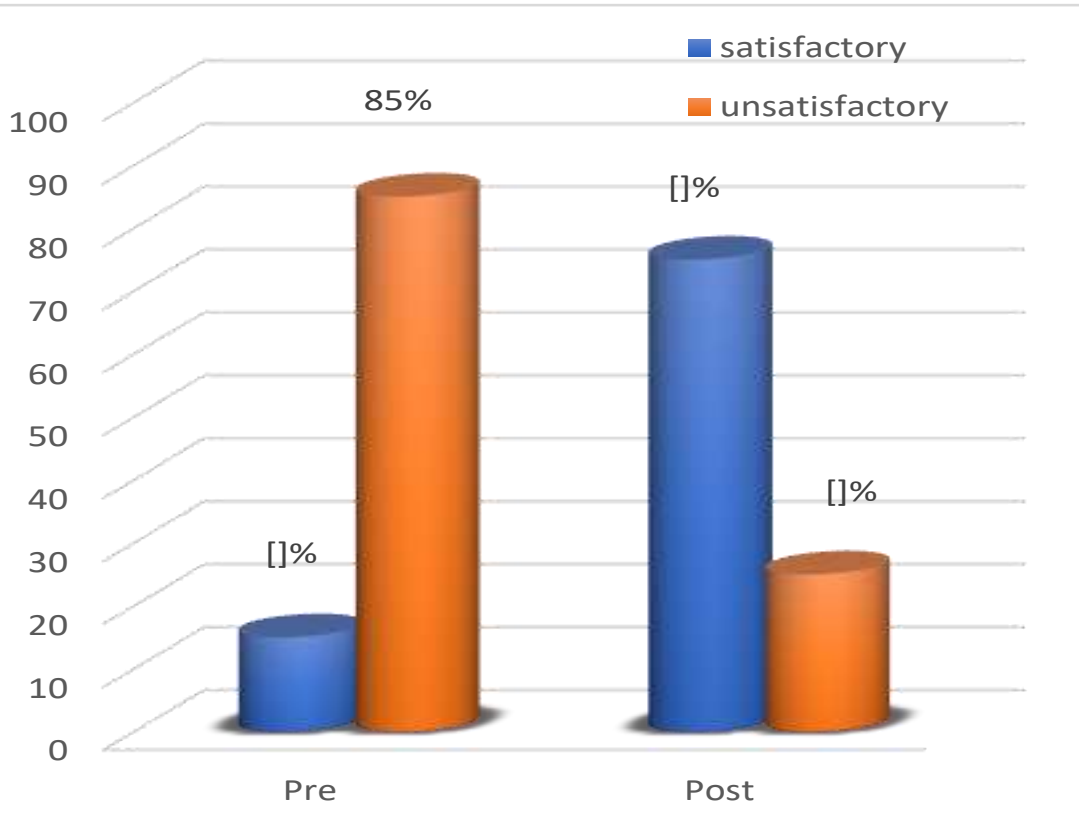

Figure (2): Comparison between the studied nurses at pre and post implementation of psychoeducational program regarding to their total performance about schizophrenia $(n=80)$.

Table (3): Relation between nurses' demographic data and their total knowledge about schizophrenia and its care at pre- psycho-educational program.

\begin{tabular}{|c|c|c|c|c|c|c|c|c|c|}
\hline \multirow{3}{*}{\multicolumn{2}{|c|}{ Nurses' demographic data }} & \multicolumn{6}{|c|}{$\begin{array}{c}\text { Total knowledge about } \\
\text { schizophrenia and its care at pre- } \\
\text { psycho-educational program }(n=80) \text {. }\end{array}$} & \multirow[t]{3}{*}{$\mathbf{X}^{2}$} & \multirow{3}{*}{$\begin{array}{l}\text { P- } \\
\text { Value }\end{array}$} \\
\hline & & \multicolumn{2}{|c|}{$\begin{array}{l}\text { Good } \\
(n=12)\end{array}$} & \multicolumn{2}{|c|}{$\begin{array}{c}\text { Average } \\
(\mathbf{n}=\mathbf{2 0})\end{array}$} & \multicolumn{2}{|c|}{$\begin{array}{l}\text { Poor } \\
(n=48\end{array}$} & & \\
\hline & & No & $\%$ & No & $\%$ & No & $\%$ & & \\
\hline \multirow[t]{3}{*}{ Age (year) } & $20-<30$ & 2 & 10 & 6 & 30 & 12 & 60 & \multirow[t]{3}{*}{1.211} & \multirow[t]{3}{*}{$>0.05$} \\
\hline & $30-<40$ & 5 & 10.9 & 10 & 21.7 & 31 & 67.4 & & \\
\hline & $\geq 40$ & 5 & 35.7 & 4 & 28.6 & 5 & 35.7 & & \\
\hline \multirow[t]{2}{*}{ Gender } & Male & 8 & 14.8 & 12 & 22.2 & 34 & 63 & \multirow[t]{2}{*}{3.541} & \multirow[t]{2}{*}{$>0.05$} \\
\hline & Female & 4 & 15.4 & 8 & 30.8 & 14 & 53.8 & & \\
\hline \multirow[t]{4}{*}{ Marital status } & Single & 2 & 12.5 & 6 & 37.5 & 8 & 50 & \multirow[t]{4}{*}{1.357} & \multirow[t]{4}{*}{$>0.05$} \\
\hline & Married & 8 & 13.8 & 11 & 19 & 39 & 67.2 & & \\
\hline & Divorced & 1 & 25 & 2 & 50 & 1 & 5 & & \\
\hline & Widowed & 1 & 50 & 1 & 50 & 0 & 0.0 & & \\
\hline
\end{tabular}

No significant at $\mathrm{p}>0.05$. 
Table (4): Relation between nurses' professional characteristics and their total knowledge about schizophrenia and its care at pre- psycho-educational program.

\begin{tabular}{|c|c|c|c|c|c|c|c|c|c|}
\hline \multirow[t]{3}{*}{$\begin{array}{c}\text { Nurses' } \\
\text { characteristics }\end{array}$} & \multirow[t]{3}{*}{ professional } & \multicolumn{6}{|c|}{$\begin{array}{c}\text { Total knowledge about } \\
\text { schizophrenia and its care at pre- } \\
\text { psycho-educational program }(\mathrm{n}=\mathbf{8 0}) \text {. }\end{array}$} & \multirow[t]{3}{*}{$\mathbf{X}^{2}$} & \multirow{3}{*}{$\begin{array}{l}\text { P- } \\
\text { Value }\end{array}$} \\
\hline & & \multicolumn{2}{|c|}{$\begin{array}{c}\text { Good } \\
(\mathbf{n}=12)\end{array}$} & \multicolumn{2}{|c|}{$\begin{array}{c}\text { Average } \\
(\mathbf{n}=20)\end{array}$} & \multicolumn{2}{|c|}{$\begin{array}{l}\text { Poor }_{(n=48)} \\
\end{array}$} & & \\
\hline & & $\overline{\text { No }}$ & $\%$ & No & $\%$ & No & $\%$ & & \\
\hline \multirow[t]{3}{*}{$\begin{array}{l}\text { Academic } \\
\text { qualification }\end{array}$} & $\begin{array}{l}\text { Diploma in } \\
\text { Nursing }\end{array}$ & 0 & 0.0 & 0 & 0.0 & 22 & 100 & \multirow[t]{3}{*}{13.64} & \multirow[t]{3}{*}{$\leq 0.001$} \\
\hline & $\begin{array}{l}\text { Diploma } \\
\text { above } \\
\text { average }\end{array}$ & 2 & 5 & 12 & 30 & 26 & 65 & & \\
\hline & $\begin{array}{l}\text { Bachelor of } \\
\text { Nursing }\end{array}$ & 10 & 55.6 & 8 & 44.4 & 0 & 0.0 & & \\
\hline \multirow{3}{*}{$\begin{array}{l}\text { Years of } \\
\text { Experience in } \\
\text { Psychiatric } \\
\text { Nursing }\end{array}$} & $<5$ & 2 & 14.3 & 2 & 14.3 & 10 & 71.4 & \multirow[t]{3}{*}{5.631} & \multirow[t]{3}{*}{$<0.05$} \\
\hline & $5-<10$ & 2 & 5 & 8 & 20 & 30 & 75 & & \\
\hline & $\geq 10$ & 8 & 30.8 & 10 & 38.4 & 8 & 30.8 & & \\
\hline \multirow{2}{*}{$\begin{array}{l}\text { Working in a } \\
\text { psychiatric } \\
\text { hospital } \\
\text { previously }\end{array}$} & Yes & 10 & 83.3 & 2 & 16.7 & 0 & 0.0 & \multirow[t]{2}{*}{15.36} & \multirow[t]{2}{*}{$\leq 0.001$} \\
\hline & No & 2 & 2.9 & 18 & 26.5 & 48 & 70.6 & & \\
\hline \multirow{2}{*}{$\begin{array}{l}\text { History of } \\
\text { taking a } \\
\text { psychiatric } \\
\text { nursing's } \\
\text { training course }\end{array}$} & Yes & 12 & 42.8 & 16 & 57.1 & 0 & 0.0 & \multirow[t]{2}{*}{14.51} & \multirow[t]{2}{*}{$\leq 0.001$} \\
\hline & No & 0 & 00 & 4 & 7.7 & 48 & 92.3 & & \\
\hline
\end{tabular}

Significant at $\mathrm{p}<0.05$. Highly statistically significant at $\mathrm{p} \leq 0.001$.

Table (5): Relation between nurses' demographic data and their total performance towards schizophrenia at pre- psycho-educational program.

\begin{tabular}{|c|c|c|c|c|c|c|c|}
\hline \multirow{3}{*}{\multicolumn{2}{|c|}{ Nurses' demographic data }} & \multicolumn{4}{|c|}{$\begin{array}{l}\text { Total performance towards } \\
\text { schizophrenia at pre- psycho- } \\
\text { educational program }(n=80) \text {. }\end{array}$} & \multirow[t]{3}{*}{$\mathbf{X}^{2}$} & \multirow[t]{3}{*}{ P-Value } \\
\hline & & \multicolumn{2}{|c|}{$\begin{array}{c}\text { Satisfactory }(n \\
=12)\end{array}$} & \multicolumn{2}{|c|}{$\begin{array}{c}\text { Unsatisfactory } \\
(n=68)\end{array}$} & & \\
\hline & & No & $\%$ & No & $\%$ & & \\
\hline \multirow[t]{3}{*}{ Age (year) } & $20-<30$ & 2 & 10 & 18 & 90 & \multirow[t]{3}{*}{2.084} & \multirow[t]{3}{*}{$>0.05$} \\
\hline & $30-<40$ & 5 & 10.9 & 41 & 89.1 & & \\
\hline & $\geq 40$ & 5 & 35.7 & 11 & 64.3 & & \\
\hline \multirow[t]{2}{*}{ Gender } & Male & 8 & 14.8 & 46 & 85.2 & \multirow[t]{2}{*}{1.967} & \multirow[t]{2}{*}{$>0.05$} \\
\hline & Female & 4 & 15.4 & 22 & 84.6 & & \\
\hline \multirow[t]{4}{*}{ Marital status } & Single & 2 & 12.5 & 14 & 87.5 & \multirow[t]{4}{*}{2.105} & \multirow[t]{4}{*}{$>0.05$} \\
\hline & Married & 8 & 13.8 & 50 & 86.2 & & \\
\hline & Divorced & 1 & 25 & 3 & 75 & & \\
\hline & Widowed & 1 & 50 & 1 & 50 & & \\
\hline
\end{tabular}

No significant at $\mathrm{p}>0.05$. 
Table (6): Relation between nurses' professional characteristics and their total performance towards schizophrenia at pre- psycho-educational program.

\begin{tabular}{|c|c|c|c|c|c|c|c|}
\hline \multirow{3}{*}{\multicolumn{2}{|c|}{ Nurses' professional characteristics }} & \multicolumn{4}{|c|}{$\begin{array}{c}\text { Total performance } \\
\text { towards schizophrenia at } \\
\text { pre- psycho-educational } \\
\text { program }(n=80) \text {. }\end{array}$} & \multirow[t]{3}{*}{$\mathbf{X}^{2}$} & \multirow[t]{3}{*}{$\begin{array}{r}P \\
\text {-Value }\end{array}$} \\
\hline & & \multicolumn{2}{|c|}{$\begin{array}{c}\text { Satisfactor } \\
\mathbf{y}(\mathbf{n}=12)\end{array}$} & \multicolumn{2}{|c|}{$\begin{array}{c}\begin{array}{c}\text { Unsatisfactory } \\
(n=68)\end{array} \\
\end{array}$} & & \\
\hline & & No & $\%$ & No & $\%$ & & \\
\hline \multirow[t]{3}{*}{ Academic qualification } & $\begin{array}{l}\text { Diploma in } \\
\text { Nursing }\end{array}$ & 0 & 0.0 & 22 & 100 & \multirow[t]{3}{*}{12.66} & \multirow[t]{3}{*}{$\leq 0.001$} \\
\hline & $\begin{array}{l}\text { Diploma above } \\
\text { average }\end{array}$ & 2 & 5 & 38 & 95 & & \\
\hline & $\begin{array}{l}\text { Bachelor of } \\
\text { Nursing }\end{array}$ & 10 & 55.6 & 8 & 44.4 & & \\
\hline \multirow{3}{*}{$\begin{array}{l}\text { Years of Experience in } \\
\text { Psychiatric Nursing }\end{array}$} & $<5$ & 2 & 14.3 & 12 & 85.7 & \multirow[t]{3}{*}{6.330} & \multirow[t]{3}{*}{$<0.05$} \\
\hline & $5-<10$ & 2 & 5 & 38 & 95 & & \\
\hline & $\geq 10$ & 8 & 30.8 & 18 & 69.2 & & \\
\hline \multirow{2}{*}{$\begin{array}{l}\text { Working in a psychiatric } \\
\text { hospital previously }\end{array}$} & Yes & 10 & 83.3 & 2 & 16.7 & \multirow[t]{2}{*}{14.91} & \multirow[t]{2}{*}{$\leq 0.001$} \\
\hline & No & 2 & 2.9 & 66 & 97.1 & & \\
\hline \multirow{2}{*}{$\begin{array}{l}\text { History of taking a } \\
\text { psychiatric nursing's } \\
\text { training course }\end{array}$} & Yes & 12 & 42.8 & 16 & 57.2 & \multirow[t]{2}{*}{15.34} & \multirow[t]{2}{*}{$\leq 0.001$} \\
\hline & No & 0 & 00 & 52 & 100 & & \\
\hline
\end{tabular}

significant at $\mathrm{p}<0.05$. Highly statistically significant at $\mathrm{p} \leq 0.001$.

Table (7): Correlation between total nurses' knowledge towards schizophrenia and their total performance at pre and post implementation of psycho-educational program.

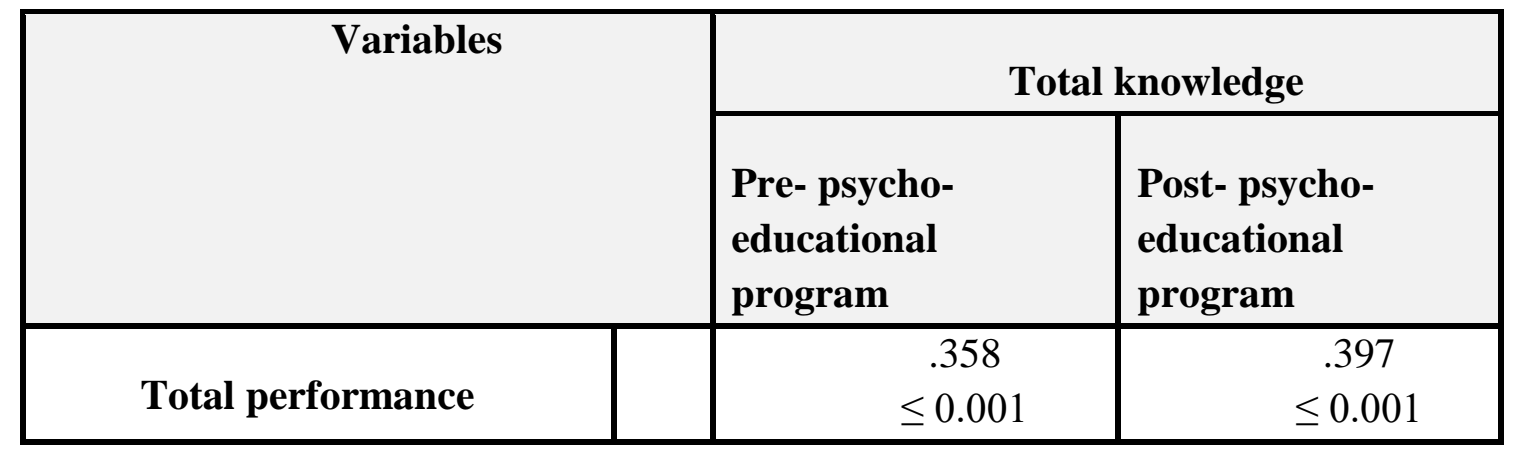

Highly statistically significant at $p \leq 0.001$.

\section{Discussion}

Regarding the socio-demographic data of the studied nurses, the present study showed that, more than half of the studied nurses their age ranged between $30-<40$ years with mean SD $35.25 \pm 4.11$ year. Related to sex and marital status, more than two-thirds of the studied nurses were male and married, respectively. These results agreed with Ahmed, (2010) reported that more than half of the nurses were males and less than half were females. As regards nurses' age more than one third were 25- year old and less than one quarter were 30- year old. As regards 
marital status less than two third were married.

Also these results were in the same line with Kumar, Mehta, \& Kalra, (2011) stated that more than half of the nurses were above 30 years of age and the majority of the nurses were male and married.

Concerning the studied nurses' professional characteristics, the present study showed that half of the studied nurses had diploma above average. Also, half of the studied nurses their years of experience in psychiatric nursing ranged between $5-<10$ years with mean SD $8.30 \pm 1.84$ year. In addition, the majority of the studied nurses working in a psychiatric hospital previously. Moreover, less than two-thirds of them did not take a psychiatric nursing's training course. These results were confirmed by EedKmalKlila \& El-SayedAbou-Abdou, (2018) mentioned that the most of the studied nurses have studied psychiatric nursing courses and near half of them have 5 to less than 10 years' experience in psychiatric field.

Regarding the distribution of the studied nurses at pre and post implementation of psycho-educational program regarding to their total knowledge about schizophrenia, the current study showed that, less than two third of nurses had poor level of total knowledge about schizophrenia and its care before program implementation. While after program implementation, more than two thirds of nurses had good level of total knowledge. These results were in accordance with White et al., (2014) reported there was statistically significant knowledge gain immediately post workshop and participants described satisfaction with the content and a willingness to apply learning from the session to their practice.
Comparison between the studied nurses at pre and post implementation of psychoeducational program regarding to their total performance towards schizophrenia, there was a marked improvement in total nurses' performance towards schizophrenia post implementation of psycho-educational program with highly statistically significant difference at $(\mathrm{P}=\leq 0.001)$ between pre and post implementation of psycho-educational program. This result may be related to that the psychoeducational program had taught the nurses about total performance towards schizophrenia that help them to build coping skills and dealing with patient's family and their relatives as required.

This result agreed with Refaay, (2019) reported that there was a statistically significant improvement between the mean score of total skills score before intervention, immediately after and after three month of intervention. There was marked increase in the overall skills of the nurses as the result of receiving an educational program about control of Suicidal Ideation among psychotic patients on nursing staff knowledge and practice.

In addition this result was in accordance with El-Salamony et al., (2019) who mentioned that there was highly significant improvement in nurses' level of knowledge and practices toward after implementation of psycho-educational program. But this result contraindicated with Willetts \& Leff, (2020) who stated that there were not statistically significant difference between the nurses skills before training program and after training program.

Regarding the relation between nurses' demographic data and their total knowledge about schizophrenia and its care at prepsycho-educational program, the present 
study revealed that, there was highly statistically significant relation between total nurses' knowledge about schizophrenia and its care at pre- psycho-educational program and their professional characteristics as Academic qualification, working in a psychiatric hospital previously and history of taking a psychiatric nursing's training course at $(\mathrm{P}=\leq$ $0.001)$. Also, there was statistically significant relation with their years of experience in psychiatric nursing at $(\mathrm{P}=\leq 0.001)$. This may be due to the academic qualification, years of experience in psychiatric nursing, working in a psychiatric hospital previously and history of taking a psychiatric nursing's training course are very important factors that had positive impact in nursing knowledge.

This result agreed with Gandhi et al., (2019) reported that there was no statistically significant relation between total nurses' knowledge about schizophrenia and its care at pre- psycho-educational program and their all socio-demographic variable

Regarding the relation between nurses' demographic data and their total performance towards schizophrenia at pre- psychoeducational program, revealed that, there was no statistically significant relation between total nurses' performance towards schizophrenia at pre- psycho-educational program and their all characteristics as age, gender and marital status at $(\mathrm{P}=>0.05)$. $)$. This may be due to the academic qualification, years of experience in psychiatric nursing, working in a psychiatric hospital previously and history of taking a psychiatric nursing's training course are very important factors that had positive impact in nursing practices. These results came in accordance with Morsy et al., (2015) who reported that there was no statistically significant relation between total nurses' performance and their socio-demographic characteristics.
Regarding the correlation between total nurses' knowledge towards schizophrenia and their total performance at pre and post implementation of psycho-educational program, the current study showed that, there was highly significant positive correlation between total nurses' knowledge towards schizophrenia and their total performance at pre and post implementation of psychoeducational program at $(\mathrm{P}=\leq 0.001)$. This result came in accordance with El-Salamony et al., (2019) who reported that there was highly significant improvement in nurses' level of knowledge and practices toward violent patient after implementation of psycho-educational program.

\section{Conclusion:}

There was a marked improvement in nurses' knowledge and performance with schizophrenic patients care post implementation of psycho-educational program with highly statistically significant difference between pre and post implementation of psycho-educational program.

\section{Recommendations:}

- The integration of the designed educational program for caregivers in pediatric oncology units would provide a framework for caregivers' role for their children with cancer.

- The psychiatric and mental health institutions should establish a committee responsible for teaching nurses newly graduated about the schizophrenic disease and its management modalities.

- The psychiatric and mental health institutions institution should maintain continuing education and orientation programs for all health team caring for patient with schizophrenic.

- Healthcare professionals, including nurses should consider developing informational 
booklets for continuous refresh their knowledge and performance.

\section{References}

Ahmed, R. (2010). Nursing intervention protocol for nurses working with psychotic patients .

Berkowitz, R., and Heinl, P. (1984): The management c I schizophrenic patients: the nurses view. Journal of Advance: Nursing; 9: 23-33.

EedKmalKlila, Z., \& El-SayedAbouAbdou, S. (2018). Nurse's Awareness of the Relationship Between Suicidal Ideation and Schizophrenic Patient's Positive/Negative Symptoms. Egyptian Journal of Health Care, 9(1), 171-186 .

El-Salamony, A. A. W., Elsher, D., AbdElgwad, Z., Shalaby, M. H., Badawy, P., \& Abd El Kareem, A. (2019). Effect of Psycho-Educational Program about Violence on Nurses' Knowledge and Practice. Tanta Scientific Nursing Journal, 16(1), 55-77 .

Fouad A and Fawzi $M$ (2013): Psychosocial Burden Among Caregivers of Patients with Schizophrenia in Egypt. Zagazig University Medical Journal. 19(5), $1-8$.

Gandhi, S., Poreddi, V., Govindan, R., Anjanappa, S., Sahu, M., Narayanasamy, P., \& Badamath, S. (2019). Knowledge and perceptions of Indian primary care nurses towards mental illness. Investigacion $\mathrm{y}$ educacion en enfermeria, 37(1), 50-59.

Hasan, A., \& Musleh, M. (2017). The impact of an empowerment intervention on people with schizophrenia: Results of a randomized controlled trial. International Journal of Social Psychiatry, 63(3), 212-223.
International Council of Nurses, (ICN) (2016): Nurses, always there for you; United against violence - anti violence tool kit Electronic Version, 17. Located at: http://www.icn.ch/indkit2001.htm (Retrieved 11.06.2006).

John, $\mathbf{S}$.(2017). The importance of continuing education as a nurse, health time, https://healthtimes.com.au/hub/nurse education/41/guidance /health insights /theimportance-of-continuing-education-as-anurse/2592.

Kumar, R., Mehta, S., \& Kalra, R. (2011). Knowledge of staff nurses regarding legal and ethical responsibilities in the field of psychiatric nursing. Nursing and Midwifery Research, 7(1), 1-11 .

Lara Adeyemi A and Paul Musco S (2019): Increase Medication Adherence and Reduce Readmissions in the Schizophrenic Patients by Educating Nurse Practitioners A Clinical Scholarly Project by.

Morsy, N. A., Shalaby, M. H., Mohamad, S., \& Elftoh, A. (2015). Educational program for Psychiatric nurses to improve their knowledge and attitude toward application of evidenced based nursing practices. Tanta Scientific Nursing Journal, 9(2), 7-28 .

Pretoruis, L., Van Dyk, A., Small, L. and Amukugo, H. (2016). An educational programme to facilitate critical thinking within the nursing perspective. International Journal of Advanced Nursing Studies, 5(2), 212.

Public Health England. (2017). Better care for people with co-occurring mental health and alcohol/drug use conditions.

Pinho, L., Pereira, A., \& Chaves, C. (2017). Nursing interventions in schizophrenia: the importance of therapeutic 
relationship. Nurse Care Open Acces J, 3(6), 00090 .

Refaay, S. (2019). Effect of psycho educational program about control of suicidal ideation among psychotic patients on nursing staffs knowledge and practice. International Journal of Advanced Research, 7, 900-919. doi: 10.21474/IJAR01/9293

Semrau, M., Evans-Lacko, S., Koschorke, M., Ashenafi, L., \& Thornicroft, G. (2015). Stigma and discrimination related to mental illness in low-and middle-income countries. Epidemiology and psychiatric sciences, 24(5), 382-394.

White, J., Hemingway, S., \& Stephenson, J. (2014). Training mental health nurses to assess the physical health needs of mental health service users: a pre-and post-test analysis. Perspectives in Psychiatric Care, 50(4), 243-250 .

Willetts L., and Leff, J. (2003): Improving the knowledge and skills of psychiatric nurses: efficacy of a staff training programme. Journal of Advanced Nursing; 42(3): 237-243.

Willetts, L., \& Leff, J. (2003). Improving the knowledge and skills of psychiatric nurses: efficacy of a staff training programme. Journal of advanced nursing, 42(3), 237-243 .

Willetts, L., \& Leff, J. (2020). Improving the knowledge and skills of psychiatric nurses: efficacy of a staff training programme. Journal of advanced nursing, 42(3), 237-243. 


\section{برنامج نفسي تربوي لتحسين معلومات وممارسات الممرضات العاملات مع مرضى الفصام \\ فاطمة عطيه متولي - غادة محم مراد - شويكار توفيق البكري- فتحيه سعيد سيد}

الفصام هو مرض عقلي خطير له خصـائص معينـة قد تشكل بعض العو ائق للعلاقة العلاجيـة. لذاهدفت

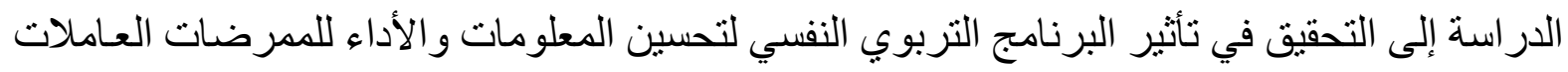

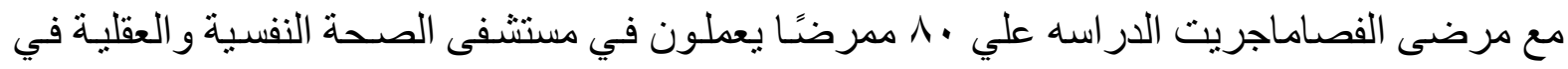

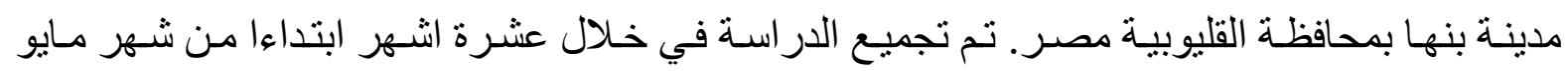

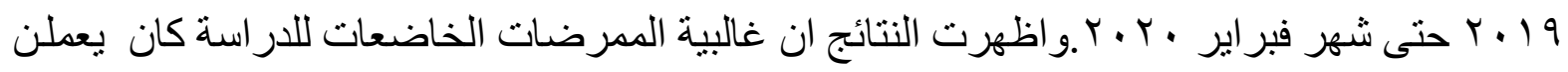

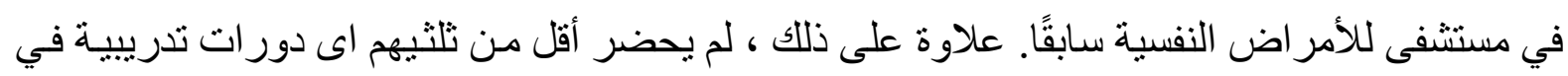

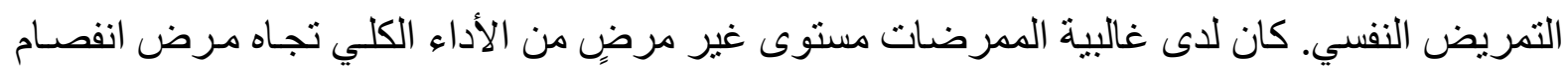

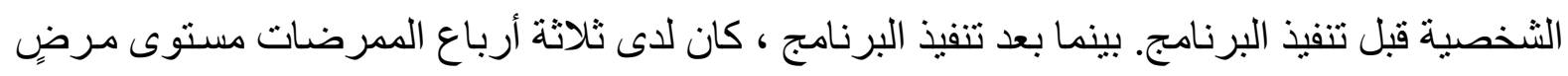

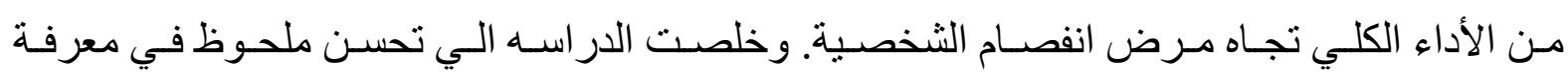

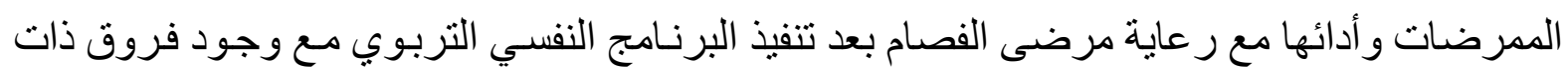

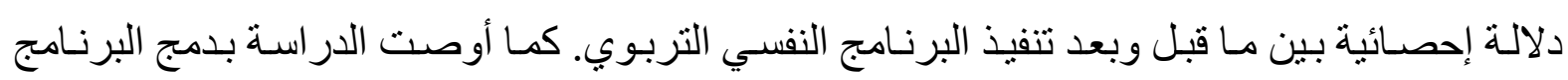

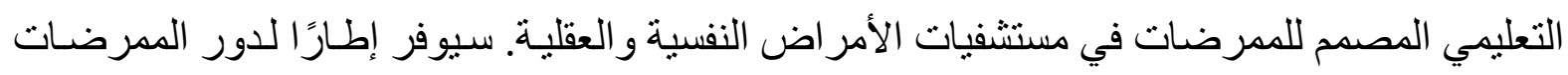
في ر عاية مرضى الفصام. 